\title{
INTEGRATED SYSTEM OF INDUSTRIAL SAFETY AND LABOR PROTECTION
}

\author{
M.A. Akbarova, V.M. Bitnyi-Shliakhto, E.U. Smirnova, A.V. Popov
}
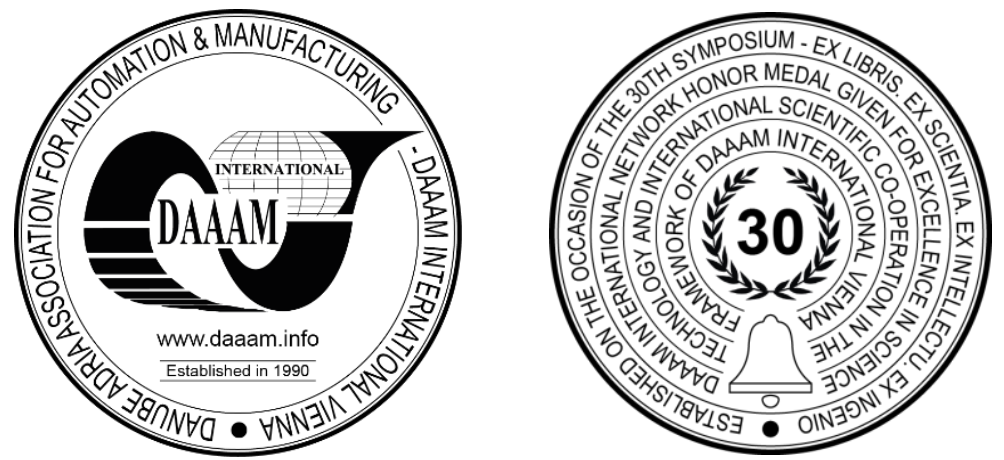

This Publication has to be referred as: Akbarova, M[arina]; Bitnyi-Shliakhto, M[arina]; Smirnova, E[katerina] \& Popov, A[.V.] (2019). Integrated System of Industrial Safety and Labor Protection, Proceedings of the 30th DAAAM International Symposium, pp.0872-0877, B. Katalinic (Ed.), Published by DAAAM International, ISBN 978-3-90273422-8, ISSN 1726-9679, Vienna, Austria

DOI: $10.2507 / 30$ th.daaam.proceedings.121

\begin{abstract}
Modern digital production (intelligent factory) is a cyber-physical production system (CFPS), which combines four main components: intelligent sensors, embedded technologies for interacting with each other or with the external environment; means of communication; cloud applications that provide semantic links between production data; terminal devices of new generation. Ensuring trouble-free operation of CFPS requires the use of appropriate industrial safety tools combined into an integrated system. Traditional data sources for the security system are stationary sources of alarm and emergency information (detectors, alarms, TV cameras, etc.) and mobile means of monitoring the territory (open and airborne). Highrisk factors for personnel, especially in construction sites and in flexible production. Internet technology technologies are available to extend the functionality of the security system. The article proposes the concept of inclusion in the security system of the subsystem of assessing the degree of danger of equipment for personnel. The proposed assessment is based on the classifier of hazards, data on the current status of the employee.
\end{abstract}

Keywords: digital production, smart factory, industrial safety, labor protection.

\section{Introduction}

The safe human system is needed to ensure human life which is a number of interconnected different systems: physical, cybernetic, territorial and organizational. All these are sources of additional vulnerability of the human system, which increase the integral risk by increasing cross-risks. A safe of community is depend on the level of security of critical infrastructure, providing the territory with basic services necessary for human life:energy, water, food, information, etc. Critical infrastructures are multi-stage, mutually overlapping systems, i.e. large complex systems that include subsystems. The paper [1] presents a model for securing critical infrastructure, and shows how to easily determine the criticality of individual infrastructures and the entire critical infrastructure.

Modern production is based on the Internet of Things technology and includes an ever-increasing number of robotic systems, including autonomous mobile robots. Along with the development of digital production, a change and improvement of the security system is required, both to protect human health and to ensure information security. With the development of cloud technologies, it is possible to receive data from equipment in real time, which opens up the possibility of using completely new business models. However, the complexity of the production model entails the need to improve the information security system. The integrated safety and security (ISS) method [2] takes into account the 
relationship between work safety and information security, for example, when information security is violated and incorrect files are transmitted in the system - this may lead to equipment malfunctions and, as a result, problems labor safety.

Working with mobile robots is also an acute problem of labor safety. Currently, in industry simple automated vehicles are used to perform basic transportation tasks. In this area there is a constant development, especially probabilistic robotics. Autonomous mobile robots are used for logistic and handling tasks. However, at the moment there are no standards to ensure safety when using mobile robotic systems. In [3], a comparison was made of three basic concepts ensuring the safety of mobile robots in production conditions. The first concept contains a protective ring that allows the mobile robot to use probabilistic robotics in combination with hazard detection sensors. The second concept considers safe navigation without probabilistic robotics, based on self-localization with reliable sensory methods. The third concept is based on a well-known map with a paved path. Virtual sensors in the form of wireless sensor networks located at the factory replace physical sensors on mobile robots. To ensure safety during the operation of mobile robots in an industrial environment, it is necessary to guarantee the detection of obstacles in advance, taking into account the necessary stopping distance and the possibility of applying an emergency stop.

In modern industrial conditions, the use of autonomous mobile robots is very common and the article [4] shows how to design and implement mobile robotic systems that can ensure labor safety in a complex industrial environment. The task was completed in three stages. The first step is to conceptualize and create a test environment. A suitable test factory was built, which was located in the office building. At the second stage, the concept of a simple workstation for various test cases was developed. In the third step, various mobile robots are created. Due to the limited space, mobile robots in this work were no more than $20 \times 20 \times 20 \mathrm{~cm}$. The authors created 4 test plants with simple workstations. Various miniature mobile robots were purchased and tested, as a result of which various risks of standards were investigated. The aim of the work was to create and test a cost-effective mobile robotic solution in an industry 4.0 environment. In Industry 4.0, mobile robots are used to transport goods between different workstations, machines and have complete autonomy of actions. Which means the ability to avoid obstacles and plan your route. A mobile robot must be designed and programmed so that it does not under any circumstances cause harm to people or other machines.

Collaboration between man and industrial robot in different ways is developing rapidly. Industrial robots that can harm people perform their tasks in separate protected areas and are regulated by safety standards. The main objective of the study [5] was the modeling and analysis of the joint work of humans and robots, monitoring the security of the system by using small industrial robots with built-in force sensors. The interaction of man and robot gives us many options that can be used in production and other related fields. An advanced multi-level system for monitoring collaboration processes can achieve the highest levels of human security with minimal downtime. Several methods have been analyzed to find the best solution for online monitoring. As a result, a multi-level security monitoring system consisting of various types of sensors and microcontrollers that can be connected to a cyber-physical production system was developed and tested.

\section{Problem statement}

Every year around the world there are hundreds of industrial accidents, most of which are the result of non-compliance with safety requirements and violation of the rules of work with the equipment. In hazardous industries, accidents are primarily caused by collisions with vehicles and moving machinery.

The main causes of accidents and deaths are:

- violation of safety requirements during operation of the equipment;

- violation of the organization of works on maintenance of the equipment;

- unsatisfactory organization of work during loading and unloading operations.

Modern digital production (smart factory) is a cyber-physical production system (CFPS), which combines four main components [6]:

- mobile smart sensors equipped with built-in technology to interact with each other or with the environment;

- means of communication, including the integration of point devices using peripheral computing technology;

- cloud application layer that provides semantic links between production data based on the ontological production model;

- terminal devices of new generation (smart phones, smart watches, etc. gadgets).

Safety and trouble-free operation are important tasks in any production and are currently provided by a set of organizational and technical measures, United by the concept of "industrial safety".

All security systems can be divided into:

- preventive, whose main task is the forecasting of emerging emergency situations to prevent;

- warning, are a "softening" layer of protection - their main purpose is to reduce the severity of the consequences of an emergency.

The traditional approach includes warning security systems - different types of sensors, alarms and simple automated workstations to which the signal is supplied, or video surveillance is conducted. In addition to sensors, the traditional approach includes route maps, workflows, and safety rules that serve to track operations and prevent emergencies.

Currently, industrial safety systems based on the principles and algorithms of machine vision are being widely implemented to provide forecasting and continuous monitoring of the situation. Along with the functions of measuring, processing, forecasting and documenting the parameters of the situation, the complex provides:

- rapid calculation of the boundaries of hazardous areas; 
- the display of the hazardous areas on the TV picture of the monitored space or object;

- the display of the hazardous areas on the working surfaces using laser pointers;

- control of personnel access to hazardous areas with changing borders and planning of safe movement in these areas.

Preventive systems are extremely complex and require the use of intelligent equipment. At the moment, there are practically no examples of a preventive industrial safety system that allows avoiding emergency situations, assessing potential accidents.

A preventive security system can be created in a smart production environment and must be part of it. Objective forecasting of the situation is possible only with the use of intelligent sensors and vision systems.

\section{Research course}

One of the key characteristics of the CFPS is proactivity [7], that is, the ability to form advanced solutions, including the identification of anomalies and alarming situations. In terms of occupational health and safety, the CFPS is an environment with constantly changing areas of greater or lesser risk to personnel. In view of these features, ensuring trouble-free and safe operation of the CFPS requires the introduction of appropriate means of industrial safety, integrated into an integrated system (ISPB). The most popular ISPS will be both at hazardous industrial facilities and at industrial sites, where many accidents are the result of collision of moving vehicles or mobile equipment.

\begin{tabular}{|l|l|}
\hline \multicolumn{1}{|c|}{ Subsystem } & \multicolumn{1}{c|}{ Functional purpose } \\
\hline $\begin{array}{l}\text { Network of stationary sensors (detectors, } \\
\text { TV cameras, etc.) }\end{array}$ & $>\begin{array}{l}\text { Equipment status (on / off / canvas) } \\
\text { Detection of abnormal, alarming, dangerous, emergency } \\
\text { situations }\end{array}$ \\
\hline Mobile robotic means of territory monitoring & $>\begin{array}{l}\text { Detection of abnormal, alarming, dangerous, emergency } \\
\text { situations in areas not covered by stationary sensors }\end{array}$ \\
\hline Navigation and communication & $>\begin{array}{l}\text { Monitoring of movements of personnel and mobile equipment } \\
\text { based on vision and radio frequency identification (RFID) } \\
\text { technologies). }\end{array}$ \\
\hline Cloud computing & $>\begin{array}{l}\text { Formation of the operational map of danger zones in relation to } \\
\text { the digital spatial model of the area and the enterprise } \\
\text { Multi-criteria analysis of the current situation } \\
\text { Situation forecasting } \\
\text { Support of decisions regarding industrial safety and labor } \\
\text { protection }\end{array}$ \\
\hline $\begin{array}{l}\text { Smartphones } \\
\text { Integrated means of informing staff functions operational } \\
\text { display of danger zones, flow alarm when approaching } \\
\text { dangerous equipment, select a safe route of travel }\end{array}$ \\
\hline Terminal device
\end{tabular}

Table 1. The structure of an integrated system of industrial safety

ISPB should have the following basic properties:

1) Traditional stationary sources of alarm and emergency information (detectors, alarms, TV cameras, etc.) should be supplemented with mobile robotic means of territory monitoring (ground and air). Since the status of each piece of equipment (on, off, idle, etc.) is constantly known in the CFS, this data must be continuously processed in the ISPS to form an operational map of the danger zones. Means of monitoring the use of personal protective equipment based on technical vision systems should be introduced;

2) Navigation and communication facilities should provide continuous monitoring of movements of personnel and mobile equipment based on technology of technical vision and radio frequency identification (RFID) [8].

3) At the level of cloud applications should be provided with the formation of an operational map of danger zones in relation to the digital spatial model of the enterprise, multi-criteria analysis of the current situation, forecast and support solutions in terms of industrial safety.

Currently, a standard on ontology for robotics and automation has been developed [9] with the presentation of the fundamental concept. This standard also defines the methodology of ontological engineering used to construct ontologies.

The purpose of this standard is to provide a methodology for the presentation of knowledge and reasoning in robotics and automation. The standard provides a unified way of representing knowledge and provides a common definition of terms, allowing unambiguous transfer of knowledge among any group of people, robots and other artificial systems.

With the growth of robotics production, the need for a standard and well-defined representation of knowledge is becoming increasingly apparent. The standard methodology of knowledge representation will allow:

- $\quad$ to define more precisely the concept of;

- to ensure mutual understanding between members of the community; 
- will facilitate the integration of data and transfer of information among robotic systems.

The intended audience for this standard are robot manufacturers, system integrators, robot end users (parts manufacturers, automotive industry, construction industry, service and solution providers, etc.), robotic equipment suppliers, robot software developers and researchers/developers. Based on this approach, a number of projects have been implemented [10-12], and we plan to use this approach in ISPB.

4) At the level of terminal devices, special means of informing personnel should be developed. The concept of the device "smart helmet" (one of the options proposed in [13]) is proposed, which, among other things, will provide an operational display of danger zones of various kinds, the supply of warning signals when the employee approaches the working equipment, the choice of the safest route of movement.
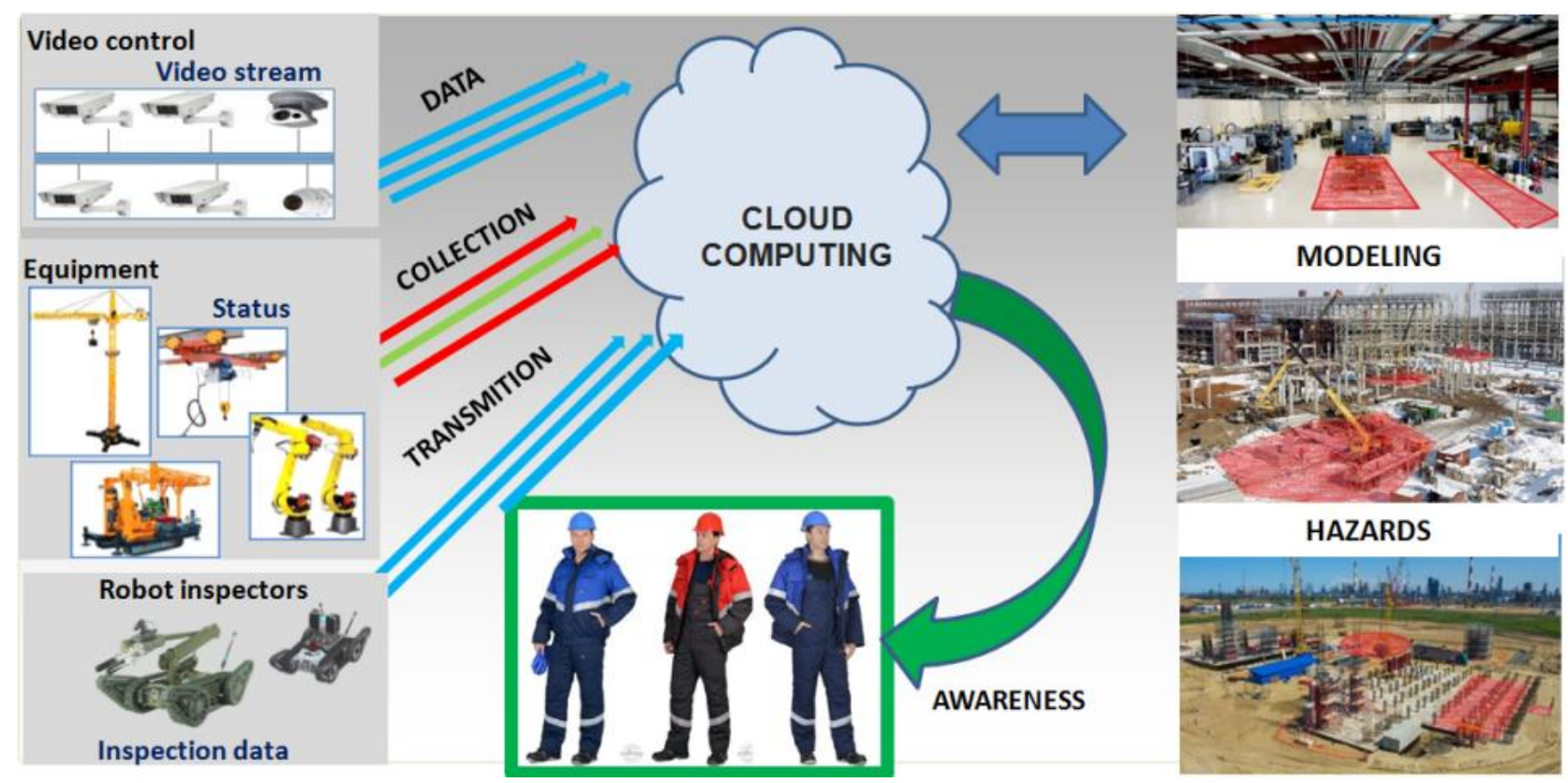

Fig. 2. Integrated security system based on CFPS.

Any production is characterized by a whole range of dangerous and harmful factors affecting humans.

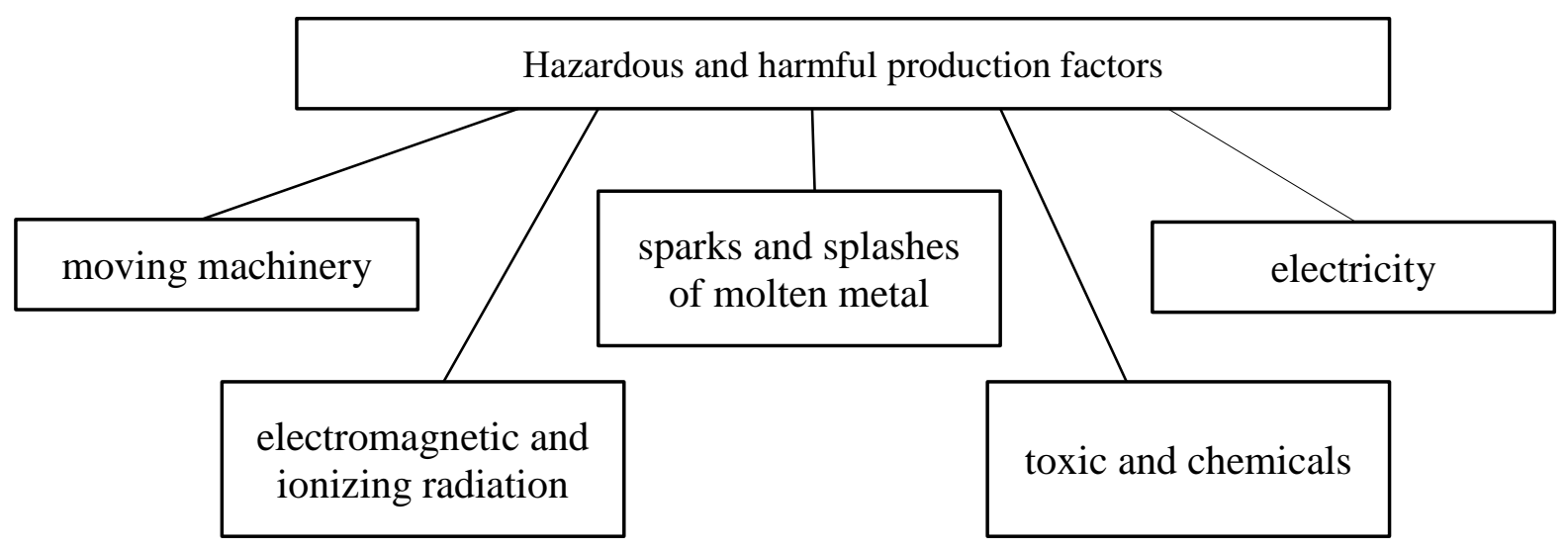

Fig. 3. Hazardous and harmful production factors/

Each factor can be assigned its own coefficient Ks (from 0 to 1, where 1 is the maximum hazard value), respectively, and each type of equipment can be assigned a certain state coefficient based on the accepted classification of harmful factors. Thus, any equipment in space will be characterized by a certain hazard coefficient Khz:

$$
\mathrm{Khz}=\mathrm{Ks} / \mathrm{R}
$$

$\mathrm{R}$ is the distance to the source of danger. The decrease in the hazard factor occurs inversely with the first power of the distance.

Let the workshop space be measured in some way in the plane of movement of the workers, i.e. there is a map on which there are stationary obstacles, which are vertical objects, then for a three-dimensional representation of a map with a route, you can use the concept of "potential field". We assume that the zone, which is characterized by a hazard 
coefficient, creates a repulsive field. To clarify the route of mobile robots, it is necessary to turn on sensors and specify the location. When sensors are in operation, real-time monitoring is required to clarify safe routes.

It must be borne in mind that, depending on the type of influencing factor, the radius of the lesion can be constant or variable, which depends on the distance to the target. For example, for a KUKA-type robotic system with a dangerous mechanical factor - collision, radius will be a constant and constant hazard coefficient for this equipment. For equipment associated with such hazardous factors as electricity, heat factor, chemical, etc. the hazard coefficient will decrease with increasing distance to the target.

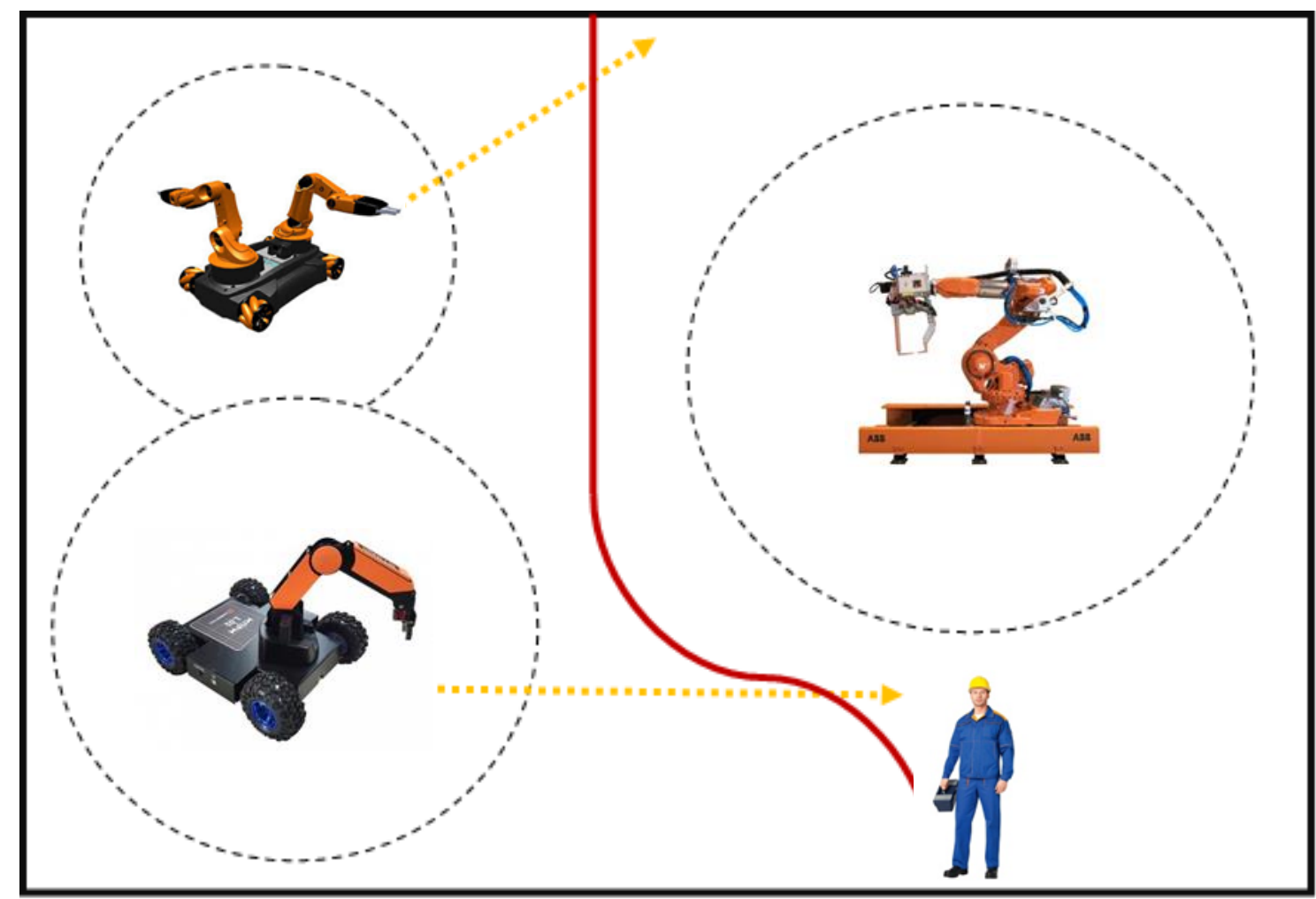

Fig. 4. Scheme of a safe route with Khz.

\section{Conclusion}

Thus, a system concept is proposed where the state of each equipment is known in real time, and on the basis of a hazard classifier, each equipment has its own hazard coefficient and, taking this into account, a route is built on mobile robotic systems and workers are notified. Further development of the concept involves a more detailed implementation of this concept in the ontology level within the ISPB.

\section{Acknowledgments}

This work was done as the part of the state task of the Ministry of Education and Science of Russia No 075-00924-19-00 "Methods of automatic synthesis of optimal control of the behavior of a group of robots on the basis of situational analysis with the use of semantic technologies».

\section{References}

[1] Prochazkova.D, Prochazka.J, Rusko.M, Mikulova.M, IIko.J. (2017) "Model for critical infrastructure safety management", Proceedings og the 28th DAAAM International Symposium, pp.0602-0610.

[2] Stuja.K, Poszvek G., Wolfel W., Markl E. (2018) "Integrated method for design and evaluation of safety and secure manufacturing systems", Proceedings og the 29th DAAAM International Symposium, pp.0157-0163.

[3] Papa M., Kaselautzke D., Stuja K., Wolfel W. (2018) "Different safety certifiable concepts for mobile robots in industrial enviroments", Proceedings og the 29th DAAAM International Symposium, pp.0791-0800.

[4] Papa M., Kaselautzke D., Radinger T., Stuja K. (2017) "Different safety certifiable concepts for mobile robots in industrial enviroments", Proceedings og the 28th DAAAM International Symposium, pp.0981-0987. 
[5] Kuts V, Sarkans M., Otto T., Tahemaa T., (2017) “ Collaborative work between human and industrial robot in manufacturing by advanced safety monitoring system", Proceedings og the 28th DAAAM International Symposium, pp.0996-1001.

[6] B. Chen, J. Wan, L. Shu, P. Li. M. Mukherjee, and B. Yin, "Smart Factory of Industry 4.0: Key Technologies, Application Case, and Challenges" IEEE Access, volume 6, pp.6505-6518, 2018.

[7] R. Burke, A. Mussomeli, S. Laaper, M. Hartigan, B. Sniderman, "The Smart factory - responsive, adaptive, connected manufacturing” Deloitte University Press, 2017.

[8] S. Lu, C. Xu, R.Y. Zhong, L.Wang, "A RFID-enabled positioning system in automated guided vehicle for smart factories” Journal of Manufacturing Systems 44, pp 179-190, 2017.

[9] IEEE 1872-2015 - IEEE Standard Ontologies foe Robotics and Automation

[10] T. Haidegger, M. Barreto, P. Goncalves, M.K. Habib, S.K.V. Ragavan, H. Li, A. Vaccarella, R. Perrone, E. Prestes "Applied ontologies and standards for service robots" Robotics and Autonomous Systems 61, pp 1215-1223, 2013.

[11] S.R. Fiorini, J.L. Carbonera, P. Goncalves, V.A.M. Jorge, V.F. Rey, T. Haidegger, M. Abel, S.A. Redfield, S. Balakirsky, V.Ragavan, H. Li, C. Schelenoff, E. Prestes. "Extensions to the core ontology for robotics and automation" Roboticsand Computer-Integrated Manufacturing 33, pp. 3-11, 2015.

[12] C. Schlenoff, A. Pietromartire, Z. Kootbally, S. Balakirsky, S. Foufou "Ontology-based state representations for intention recognition in human-robot collaborative environments" Robotics and Autonomous Systems 61, pp. 1224-1234, 2013.

[13] https://softline.com/ru/smart_business/article/new-challenges-of-production-from-needs-to-solutions-softline 